\title{
The enhancement of propyl gallate-induced apoptosis in HeLa cells by a proteasome inhibitor MG132
}

\author{
BO RA YOU and WOO HYUN PARK \\ Department of Physiology, Medical School, Institute for Medical Sciences, \\ Chonbuk National University, JeonJu 561-180, Republic of Korea
}

Received October 12, 2010; Accepted December 2, 2010

DOI: $10.3892 /$ or.2010.1121

\begin{abstract}
Propyl gallate (PG) used in processed food and medicinal preparations has been shown to induce cell death in normal and cancer cells. The inhibition of proteasome function has emerged as a useful strategy to maneuver apoptosis. Here, we investigated the combined effects of PG and MG132 (a proteasome inhibitor) on HeLa cells in relation to cell growth, cell death, reactive oxygen species (ROS) and glutathione (GSH). PG induced growth inhibition and apoptosis in HeLa cells, accompanied by the loss of mitochondrial membrane potential (MMP; $\Delta \Psi_{\mathrm{m}}$ ), activation of caspase 3 and PARP cleavage. The levels of ROS and GSH depletion were increased in PG-treated HeLa cells. MG132 intensified apoptosis and PARP cleavage in PG-treated HeLa cells. MG132 also increased ROS levels including mitochondrial $\mathrm{O}_{2}{ }^{-}$, MMP $\left(\Delta \Psi_{\mathrm{m}}\right)$ loss and GSH depletion in PGtreated HeLa cells. PG induced a G1 phase arrest of the cell cycle in HeLa cells, which was significantly prevented by MG132. MG132 alone inhibited HeLa cell growth via inducing the cell cycle arrests and triggering apoptosis. Conclusively, the inhibition of proteasome by MG132 plays a role as an enhancement factor in PG-induced apoptosis of HeLa cells via increasing ROS levels and GSH depletion.
\end{abstract}

\section{Introduction}

Propyl gallate (PG) is used as a synthetic antioxidant in processed food and cosmetics to prevent rancidity and spoilage

Correspondence to: Dr Woo Hyun Park, Department of Physiology, Medical School, Institute for Medical Sciences, Chonbuk National University, JeonJu 561-180, Republic of Korea

E-mail: parkwh71@chonbuk.ac.kr

Abbreviations: PG, propyl gallate; MG132, carbobenzoxy-LeuLeu-leucinal; ROS, reactive oxygen species; CDK, cyclin-dependent kinase; SOD, superoxide dismutase; MMP $\left(\Delta \Psi_{\mathrm{m}}\right)$, mitochondrial membrane potential; FBS, fetal bovine serum; PI, propidium iodide; FITC, fluorescein isothiocyanate; $\mathrm{H}_{2} \mathrm{DCFDA}, 2^{\prime}$, 7'-dichlorodihydrofluorescein diacetate; DHE, dihydroethidium; GSH, glutathione; CMFDA, 5-chloromethylfluorescein diacetate

Key words: propyl gallate, MG132, apoptosis, HeLa, reactive oxygen species, glutathione
(1). Because of its ubiquitous usage, the potential toxicity of PG has been investigated to assess various toxicological properties of mutagenicity (2) and cytogenetic effects (3). Despite the unspecified low toxicity of PG, it exerts a variety of effects on tissue and cell functions. Several studies demonstrate the benefits of PG as an antioxidant $(4,5)$ and a chemopreventive agent (6). In contrast, PG can exert prooxidant properties $(7,8)$. It is reported that PG is cytotoxic to isolated rat hepatocytes via mitochondrial dysfunction (9). In addition, PG has been shown to induce cell death in umbilical vein or pulmonary artery endothelial cells $(10,11)$. It is suggested that antioxidative and cytoprotective properties of PG may change to prooxidative, cytotoxic and genotoxic properties in the presence of $\mathrm{Cu}$ (II) (12).

The ubiquitin-proteasomal system represents the major non-lysosomal pathway through which intracellular proteins related to cell cycle, differentiation and apoptosis are degraded in eukaryotic cells $(13,14)$. The perturbation of proteasome function has emerged as a useful strategy to maneuver apoptosis. MG132 (carbobenzoxy-Leu-Leu-leucinal) as a peptide aldehyde efficiently blocks the proteolytic activity of proteasome complex (15). Proteasome inhibitors including MG132 have been demonstrated to induce apoptotic cell death through formation of reactive oxygen species (ROS) $(16,17)$. ROS formation and GSH (glutathione) depletion due to proteasome inhibitors may cause mitochondrial dysfunction and subsequent cytochrome c release, which leads to cell viability loss $(18,19)$.

Recently, we demonstrated that PG inhibited the growth of HeLa cells via apoptosis and GSH depletion $(20,21)$ and MG132 inhibited the growth of HeLa cells via cell cycle arrest as well as apoptosis (22). In the present study, we investigated the combined effects of PG and MG132 on HeLa cells in relation to cell growth, cell cycle and apoptosis. Furthermore, we evaluated the changes of ROS and GSH levels in HeLa cells treated with PG and MG132.

\section{Materials and methods}

Cell culture. The human cervical HeLa cells were obtained from the American Type Culture Collection (ATCC, Manassas, VA) and maintained in a humidified incubator containing 5\% $\mathrm{CO}_{2}$ at $37^{\circ} \mathrm{C}$. HeLa cells were cultured in RPMI-1640 (SigmaAldrich Chemical Co., St. Louis, MO) supplemented with $10 \%$ fetal bovine serum (FBS; Sigma-Aldrich Chemical Co.) and $1 \%$ penicillin-streptomycin (Gibco BRL, Grand Island, NY). 
Reagents. PG purchased from the Sigma-Aldrich Chemical Co. was dissolved in ethanol at $200 \mathrm{mM}$ as a stock solution. MG132 was purchased from Calbiochem (San Diego, CA). It was dissolved in DMSO solution buffer at $10 \mathrm{mM}$ as a stock solution. Ethanol $(0.2 \%)$ and DMSO $(0.2 \%)$ were used as a control vehicle. All stock solutions were wrapped in foil and kept at $-20^{\circ} \mathrm{C}$.

Cell growth assay. The effect of PG and/or MG132 on HeLa cell growth was determined by trypan blue exclusion cell counting or measuring 3-(4,5-dimethylthiazol-2-yl)-2,5diphenyltetrazolium bromide (MTT; Sigma-Aldrich Chemical Co.) dye absorbance of living cells as previously described (23). In brief, $3 \times 10^{4}$ cells per well were seeded in 96-well microtiter plates (Nunc) for cell counting and MTT assays. After exposure to the indicated amounts of PG with or without MG132 for $24 \mathrm{~h}$, cells were collected with trypsin digestion for trypan blue exclusion cell counting or were used for MTT assays. Twenty microliters of MTT solution ( $2 \mathrm{mg} / \mathrm{ml}$ in PBS) was added to each well of the 96 -well plates. The plates were incubated for 4 additional hours at $37^{\circ} \mathrm{C}$. Media in plates were withdrawn by pipetting, and $200 \mu 1$ of DMSO was added to each well to solubilize the formazan crystals. Optical density was measured at $570 \mathrm{~nm}$ using a microplate reader (Spectra MAX 340, Molecular Devices Co., Sunnyvale, CA).

Western blot analysis. The expressions of proteins were evaluated using Western blot analysis, as previously described (24). In brief, $1 \times 10^{6}$ cells were incubated with indicated amounts of PG with or without MG132 for $24 \mathrm{~h}$. The cells were then washed in PBS and suspended in 5 volumes of lysis buffer (20 mM HEPES pH 7.9, 20\% glycerol, $200 \mathrm{mM}$ $\mathrm{KCl}, 0.5 \mathrm{mM}$ EDTA, 0.5\% NP40, $0.5 \mathrm{mM}$ DTT, $1 \%$ protease inhibitor cocktail). Supernatant protein concentrations were determined using the Bradford method. Supernatant samples containing $40 \mu \mathrm{g}$ total protein were resolved by 8 or $15 \%$ SDS-PAGE gels, depending on the sizes of target proteins, transferred to Immobilon-P PVDF membranes (Millipore, Billerica, MA) by electroblotting, and then probed with antiubiquitin, anti-p27, caspase-3, PARP, catalase, SOD1 and anti-B-actin antibodies (Santa Cruz Biotechnology, Santa Cruz, CA). Membranes were incubated with horseradish peroxidaseconjugated secondary antibodies. Blots were developed using an ECL kit (Amersham, Arlington Heights, IL).

Cell cycle analysis. Cell cycle distributions were determined by propidium iodide (PI, Sigma-Aldrich; Ex/Em = 488/ $617 \mathrm{~nm}$ ) staining, as previously described (25). In brief, $1 \times 10^{6}$ cells were incubated with the indicated amounts of PG with or without MG132 for $24 \mathrm{~h}$. Cells were then washed with PBS and fixed in $70 \%$ ethanol. Cells were washed again with PBS, then incubated with PI $(10 \mu \mathrm{g} / \mathrm{ml})$ with simultaneous RNase treatment at $37^{\circ} \mathrm{C}$ for $30 \mathrm{~min}$. Cell DNA content was measured using a FACStar flow cytometer (Becton-Dickinson, San Jose, CA).

Annexin $V$ staining. Apoptosis was determined by staining cells with Annexin V-fluorescein isothiocyanate (FITC, PharMingen, San Diego, CA; Ex/Em = 488/519 nm), as previously described (25). In brief, $1 \times 10^{6}$ cells were incubated with the indicated amounts of PG with or without MG132 for
24 h. Cells were washed twice with cold PBS and then resuspended in $500 \mu 1$ of binding buffer (10 mM HEPES/ $\mathrm{NaOH}$ pH 7.4, $140 \mathrm{mM} \mathrm{NaCl}, 2.5 \mathrm{mM} \mathrm{CaCl}_{2}$ ) at a concentration of $1 \times 10^{6}$ cells $/ \mathrm{ml}$. Five microliters of Annexin V-FITC was then added to these cells, which were analyzed with a FACStar flow cytometer (Becton-Dickinson).

Measurement of MMP $\left(\Delta \Psi_{m}\right)$. MMP $\left(\Delta \Psi_{\mathrm{m}}\right)$ levels were measured using rhodamine 123 fluorescent dye (Sigma; $\mathrm{Ex} / \mathrm{Em}=485 / 535 \mathrm{~nm}$ ), as previously described (23). In brief, $1 \times 10^{6}$ cells were incubated with the indicated amounts of PG with or without MG132 for $24 \mathrm{~h}$. Cells were washed twice with PBS and incubated with rhodamine $123(0.1 \mu \mathrm{g} / \mathrm{ml})$ at $37^{\circ} \mathrm{C}$ for $30 \mathrm{~min}$. Rhodamine 123 staining intensity was determined by flow cytometry. An absence of rhodamine 123 from cells indicated the loss of MMP $\left(\Delta \Psi_{\mathrm{m}}\right)$ in cells. The MMP $\left(\Delta \Psi_{\mathrm{m}}\right)$ levels in the cells, excluding MMP $\left(\Delta \Psi_{\mathrm{m}}\right)$ loss cells, were expressed as the mean fluorescence intensity (MFI), which was calculated by CellQuest software (BectonDickinson).

Detection of intracellular ROS. Intracellular ROS were detected by fluorescent probe dye, 2',7'-dichlorodihydrofluorescein diactate $\left(\mathrm{H}_{2} \mathrm{DCFDA}\right.$, Invitrogen Molecular Probes, $\mathrm{OR}$; $\mathrm{Ex} / \mathrm{Em}=495 / 529 \mathrm{~nm}) . \mathrm{H}_{2} \mathrm{DCFDA}$ is poorly selective for superoxide anion radical $\left(\mathrm{O}_{2}{ }^{-}\right)$. In contrast, dihydroethidium (DHE; Invitrogen Molecular Probes; Ex/Em = 518/605 nm) is a fluorogenic probe that is highly selective for $\mathrm{O}_{2}{ }^{-}$among ROS. In addition, mitochondrial $\mathrm{O}_{2}{ }^{--}$level was detected by means of MitoSOX ${ }^{\mathrm{TM}}$ Red mitochondrial $\mathrm{O}_{2}{ }^{--}$indicator (Invitrogen Molecular Probes; Ex/Em = 510/580 nm) as previously described (26). In brief, $1 \times 10^{6}$ cells were incubated with the indicated amounts of PG with or without MG132 for 1 or $24 \mathrm{~h}$. Cells were then washed in PBS and incubated with $20 \mu \mathrm{M} \mathrm{H}_{2}$ DCFDA, $20 \mu \mathrm{M}$ DHE or $5 \mu \mathrm{M}$ MitoSOX $^{\mathrm{TM}}$ Red agent at $37^{\circ} \mathrm{C}$ for 30 min according to the instructions of the manufacturer. DCF, DHE and MitoSOX fluorescences were detected using a FACStar flow cytometer (Becton-Dickinson). ROS and $\mathrm{O}_{2}{ }^{-}$levels were expressed as mean fluorescence intensity (MFI), which was calculated by CellQuest software (Becton-Dickinson).

Detection of the intracellular glutathione (GSH). Cellular GSH levels were analyzed using 5-chloromethylfluorescein diacetate (CMFDA, Invitrogen Molecular Probes; Ex/Em = $522 / 595 \mathrm{~nm}$ ), as previously described (26). In brief, $1 \times 10^{6}$ cells were incubated with the indicated amounts of PG with or without MG132 for 1 or $24 \mathrm{~h}$. Cells were then washed with PBS and incubated with $5 \mu \mathrm{M}$ CMFDA at $37^{\circ} \mathrm{C}$ for $30 \mathrm{~min}$. CMF fluorescence intensity was determined using a FACStar flow cytometer (Becton-Dickinson). Negative CMF staining (GSH-depleted) cells were expressed as the percent of (-) CMF cells. The CMF levels in cells, excluding GSH-depleted cells, were expressed as mean fluorescence intensity (MFI), which was calculated by CellQuest software (BectonDickinson).

Statistical analysis. The results represent the mean of at least three independent experiments (mean \pm SD). The data were 
A

B
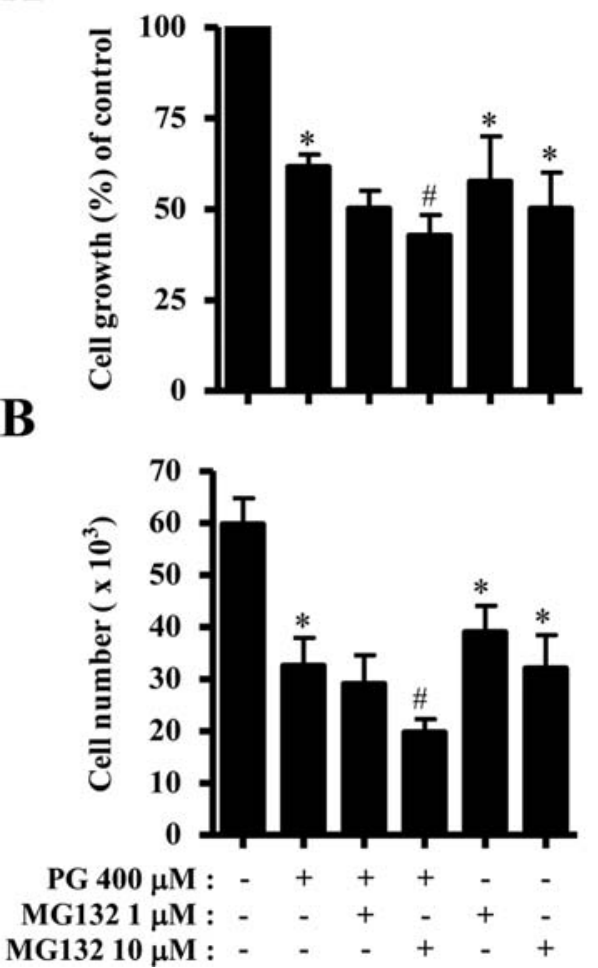

C

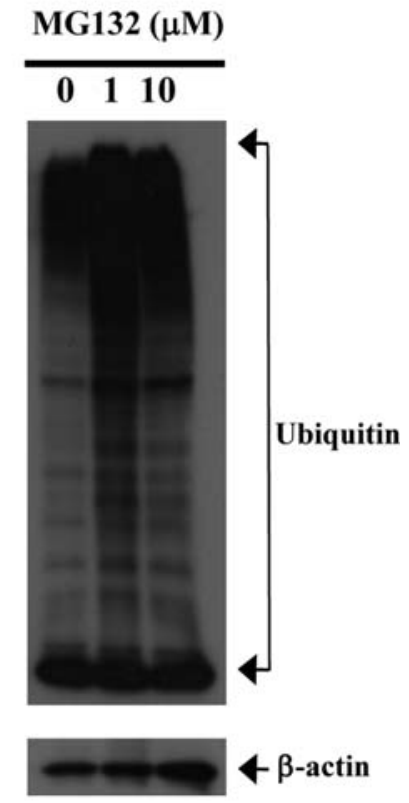

Figure 1. Effects of MG132 on the growth in PG-treated HeLa cells. Exponentially growing cells were treated with PG and/or MG132 for 24 h. Cell growth (A) and cell number (B) were assessed by an MTT assay and trypan blue exclusion cell counting, respectively. (C) $40 \mu \mathrm{g}$ samples of protein extracts were resolved by SDS-PAGE gel, transferred onto the PVDF membranes and immunoblotted with the indicated antibodies against ubiquitin and $\beta$-actin. ${ }^{*} \mathrm{P}<0.05$ compared with the control group. ${ }^{\#} \mathrm{P}<0.05$ compared with cells treated with $\mathrm{PG}$ only.

analyzed using Instat software (GraphPad Prism4, San Diego, CA). The Student's t-test or one-way analysis of variance (ANOVA) with post hoc analysis using Tukey's multiple comparison test was used for parametric data. Statistical significance was defined as $\mathrm{P}<0.05$.

\section{Results}

Effects of MG132 on cell growth and the cell cycle distribution in PG-treated HeLa cells. For this experiment, the dose of $400 \mu \mathrm{M}$ PG was chosen to be a suitable concentration, which inhibited the growth of HeLa cells about 35\% using an MTT assay (Fig. 1A) and about 50\% using trypan blue cell counting at $24 \mathrm{~h}$ (Fig. 1B). MG132 dose-dependently increased the growth inhibition of PG-treated HeLa cells (Fig. 1A and B). MG132 alone inhibited the growth of HeLa control cells (Fig. 1A and B). In addition, we observed a relative increase in anonymous ubiquitinated proteins in MG132-treated HeLa cells (Fig. 1C), suggesting that MG132 inhibits the activity of $26 \mathrm{~S}$ proteasome complex in HeLa cells. In relation to cell cycle distributions, PG significantly induced a G1 phase arrest of the cell cycle at $24 \mathrm{~h}$ (Fig. 2). MG132 significantly inhibited a G1 phase arrest in PG-treated HeLa cells (Fig. 2). Treatment with 1 and $10 \mu \mathrm{M}$ MG132 alone significantly arrest G2-M phase and S phase of the cell cycle, respectively (Fig. 2). In addition, p27, a cyclindependent kinase inhibitor which typically causes cells to arrest in the G1 phase, was increased in PG-treated HeLa cells, but MG132 completely decreased the p27 protein level (Fig. 2).

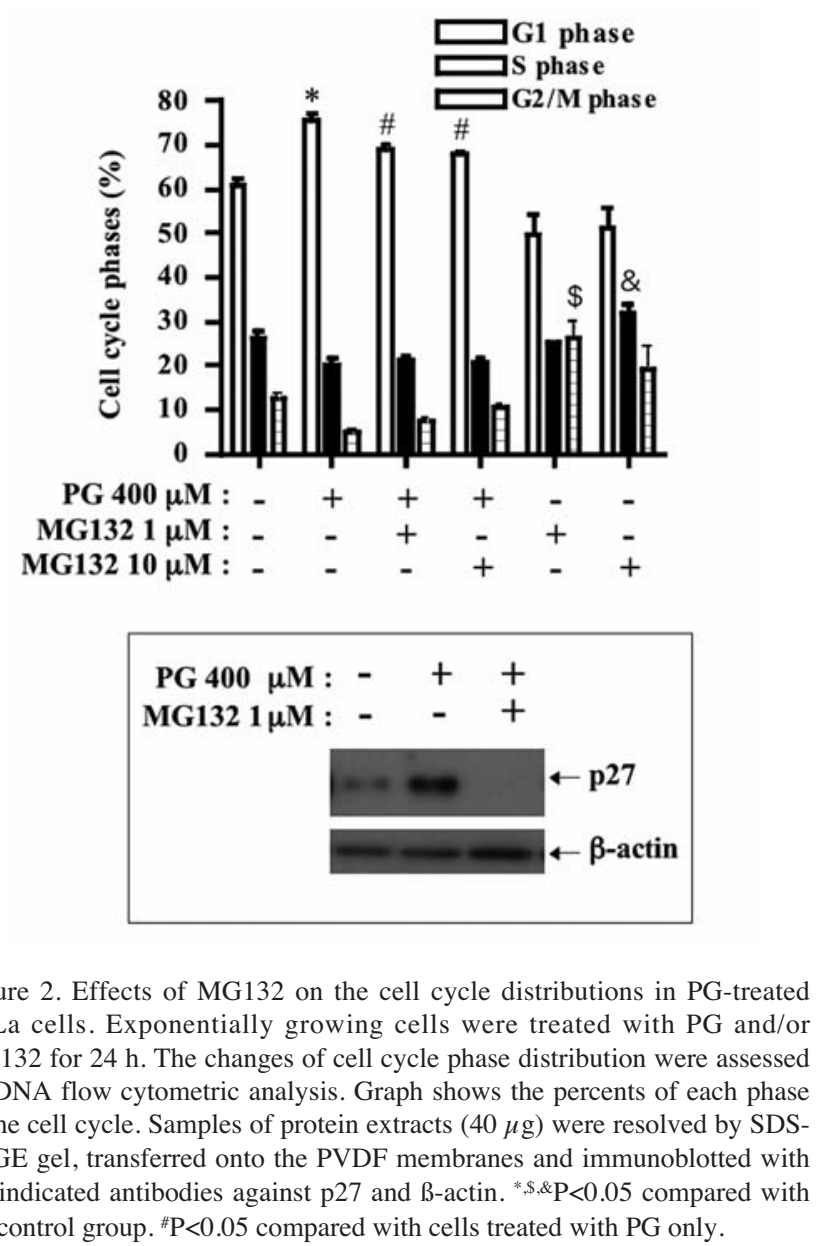


A

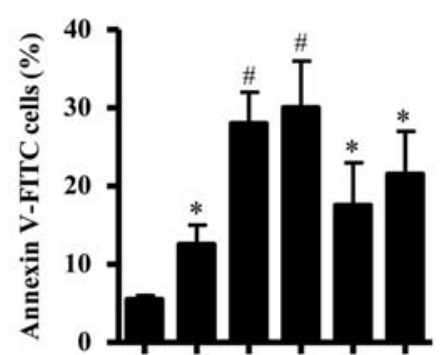

PG $400 \mu \mathrm{M}$ : MG132 $1 \mu \mathrm{M}$ : MG132 $10 \mu \mathrm{M}$ :
B

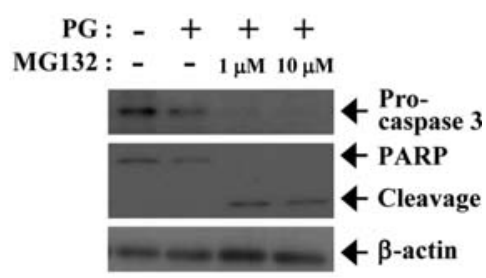

C

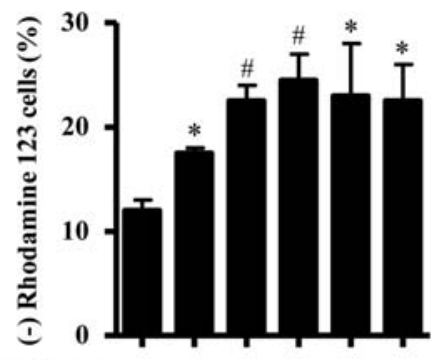

PG $400 \mu \mathrm{M}:-+++-$ MG132 1 $\mu \mathrm{M}$ : : - +-+
D

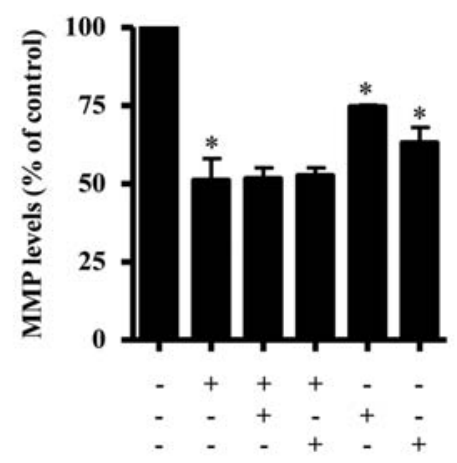

Figure 3. Effects of MG132 on apoptosis and MMP $\left(\Delta \Psi_{\mathrm{m}}\right)$ in PG-treated HeLa cells. Exponentially growing cells were treated with PG and/or MG132 for 24 h. Annexin V-FITC cells and MMP $\left(\Delta \Psi_{\mathrm{m}}\right)$ in HeLa cells were measured with a FACStar flow cytometer. (A) Graph shows the percent of Annexin V positive staining cells. (B) $40 \mu \mathrm{g}$ samples of protein extracts were resolved by SDS-PAGE gel, transferred onto the PVDF membranes and immunoblotted with the indicated antibodies against caspase-3, PARP and $B$-actin. (C and D) Graphs show the percent of rhodamine 123 negative $\left[\mathrm{MMP}\left(\Delta \Psi_{\mathrm{m}}\right)\right.$ loss] cells $(\mathrm{C})$ and $\operatorname{MMP}\left(\Delta \Psi_{\mathrm{m}}\right)$ levels compared with HeLa control cells (D). ${ }^{*} \mathrm{P}<0.05$ compared with the control group. ${ }^{\#} \mathrm{P}<0.05$ compared with cells treated with $\mathrm{PG}$ only.

Effects of MG132 on apoptosis and $M M P\left(\Delta \Psi_{m}\right)$ in $P G$ treated HeLa cells. PG induced apoptosis in HeLa cells, as evidenced by Annexin V staining (Fig. 3A). MG132 increased the number of Annexin V-FITC positive cells in PG-treated or untreated HeLa cells (Fig. 3A). In relation to apoptosis-related proteins, the level of procaspase-3 was significantly reduced in PG-treated HeLa cells (Fig. 3B), which implied that the activation of caspase- 3 occurred in PG-treated cells. MG132 enhanced the decrease of procaspase-3 (Fig. 3B). In addition, cleavage of PARP [poly (ADP-ribose) polymerase] provides one of the most recognizable examples in apoptosis (27). As shown in Fig. 3B, the intact $116 \mathrm{kDa}$ moiety of PARP protein was decreased in PG-treated HeLa cells. MG132 clearly induced the cleavage of PARP in PG-treated HeLa cells (Fig. 3B). In relation to MMP $\left(\Delta \Psi_{\mathrm{m}}\right)$, the loss of MMP $\left(\Delta \Psi_{\mathrm{m}}\right)$ was observed in PG-treated cells at $24 \mathrm{~h}$ (Fig. 3C). MG132 increased the level of MMP $\left(\Delta \Psi_{\mathrm{m}}\right)$ loss in PG-treated or untreated HeLa cells (Fig. 3C). In addition, PG reduced MMP $\left(\Delta \Psi_{\mathrm{m}}\right)$ level [excluding MMP $\left(\Delta \Psi_{\mathrm{m}}\right)$ loss cells] about $50 \%$ compared with control cells (Fig. 3D). MG132 did not affect the MMP $\left(\Delta \Psi_{\mathrm{m}}\right)$ level in PG-treated cells (Fig. 3D). This agent alone reduced the MMP $\left(\Delta \Psi_{\mathrm{m}}\right)$ level in HeLa control cells (Fig. 3D).

Effects of MG132 on ROS and $\mathrm{O}_{2}^{-}$- levels in PG-treated HeLa cells. Intracellular ROS level (as detected by DCF) was decreased in PG-treated cells at the short time period of $1 \mathrm{~h}$ (Fig. 4A) whereas ROS level was increased at 24 h (Fig. 4B). MG132 increased ROS levels in PG-treated and untreated HeLa cells at 1 and $24 \mathrm{~h}$ (Fig. 4A and B). Furthermore, PG slightly increased the expression level of catalase in HeLa cells whereas MG132 decreased the level in PG-treated cells (Fig. 4C). PG slightly decreased SOD expression level in HeLa cells and MG132 did not affect the level in PG-treated or untreated HeLa cells (Fig. 4C). Furthermore, red fluorescence derived from DHE reflecting intracellular $\mathrm{O}_{2}{ }^{-}$- level was increased in PG-treated cells at 1 and $24 \mathrm{~h}$ (Fig. 4D and E). MG132 intensified the increased $\mathrm{O}_{2}{ }^{--}$levels in PGtreated and untreated cells at $24 \mathrm{~h}$ (Fig. 4D and E). In addition, MitoSOX Red fluorescence level, which specifically indicates $\mathrm{O}_{2}{ }^{-}$level in the mitochondria, was increased in PG-treated HeLa cells at $24 \mathrm{~h}$ (Fig. 4F). MG132 increased the mitochondrial $\mathrm{O}_{2}{ }^{-}$levels in PG-treated and untreated HeLa cells (Fig. 4F).

Effects of MG132 on GSH levels in PG-treated HeLa cells. Next, the changes of GSH contents in HeLa cells were determined at 1 or $24 \mathrm{~h}$. PG increased the number of GSH depletion cells about $7 \%$ at $24 \mathrm{~h}$ compared with HeLa control cells (Fig. 5A and B) but not at $1 \mathrm{~h}$ (data not shown). MG132 increased GSH depleted cell numbers in PG-treated and untreated HeLa cells (Fig. 5A and B). In addition, PG did not 
A

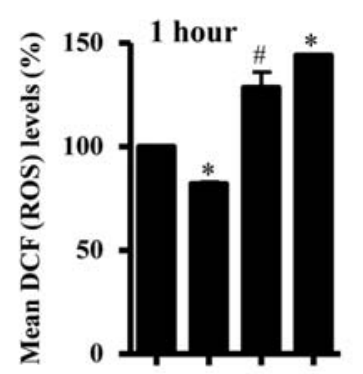

PG $400 \mu \mathrm{M}$ : - + + -

MG132 1 $\mu \mathrm{M}:-{ }^{-}-$ MG132 $10 \mu \mathrm{M}$ :

D

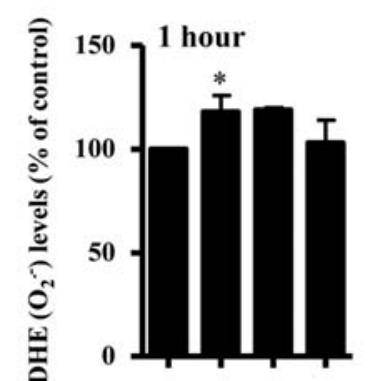

PG $400 \mu \mathrm{M}:-++$

MG132 $1 \mu \mathrm{M}$ :

MG132 $10 \mu \mathrm{M}$ :
B

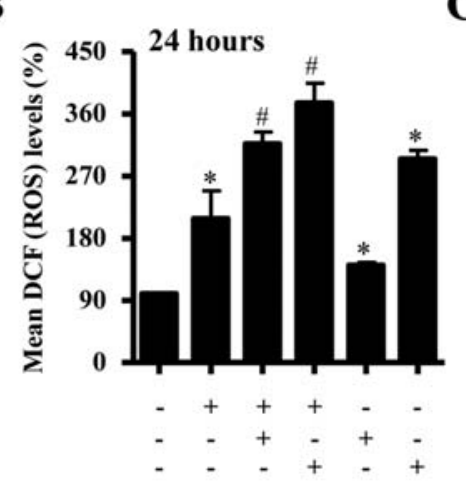

E

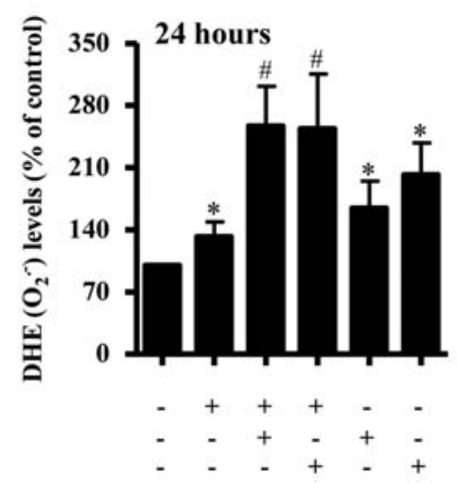

C

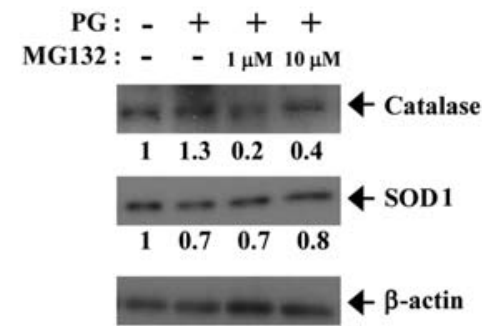

F

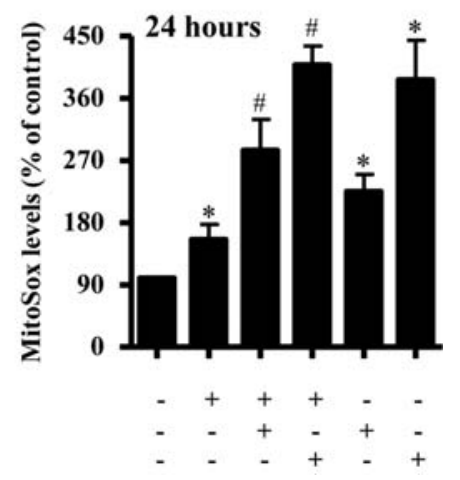

Figure 4. Effects of MG132 on ROS levels in PG-treated HeLa cells. Exponentially growing cells were treated with PG and/or MG132 for 1 or 24 h. ROS levels in HeLa cells were measured using a FACStar flow cytometer. (A and B) Graphs indicate DCF (ROS) levels (\%) compared with control cells at $1 \mathrm{~h}$ (A) and at $24 \mathrm{~h}$ (B). (C) $40 \mu \mathrm{g}$ samples of protein extracts were resolved by SDS-PAGE gel, transferred onto the PVDF membranes and immunoblotted with the indicated antibodies against catalase, SOD1 and $\beta$-actin. The values under Western blotting indicate the ratio of protein expression levels compared with each B-actin control band. (D and E) Graphs indicate DHE $\left(\mathrm{O}_{2}^{\circ}\right)$ levels (\%) compared with control cells at $1 \mathrm{~h}(\mathrm{D})$ and $24 \mathrm{~h}(\mathrm{E})$. (F) Graph shows the percent of MitoSOX (mitochondrial $\mathrm{O}_{2}{ }^{*}$ ) levels compared with control cells at $24 \mathrm{~h} .{ }^{*} \mathrm{P}<0.05$ compared with the control group. ${ }^{*} \mathrm{P}<0.05$ compared with cells treated with PG only.

A

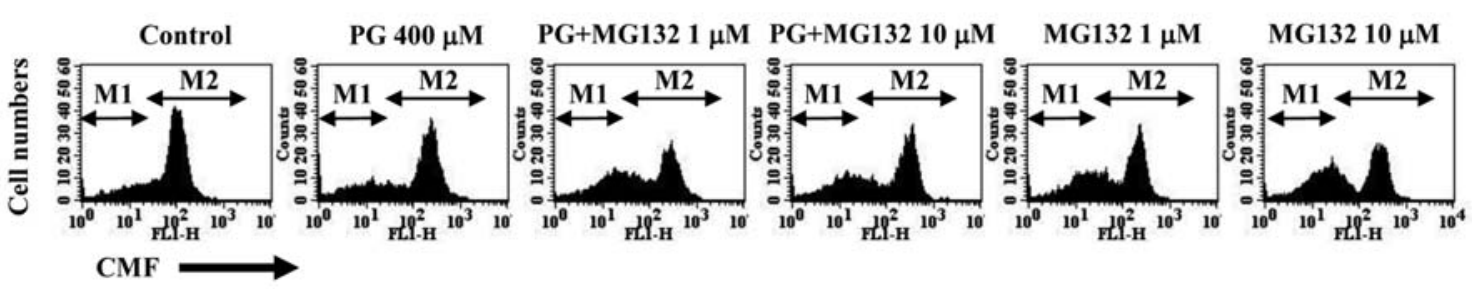

B

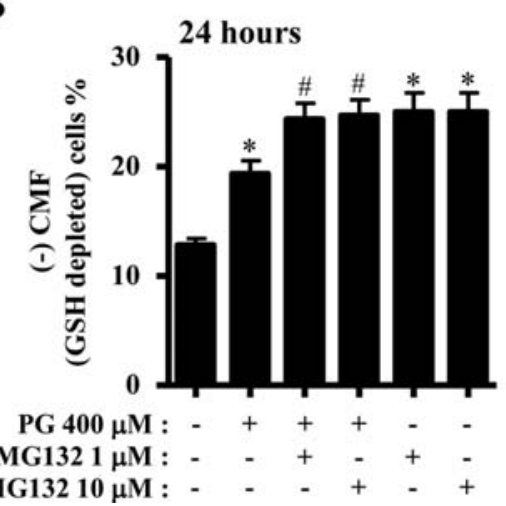

C

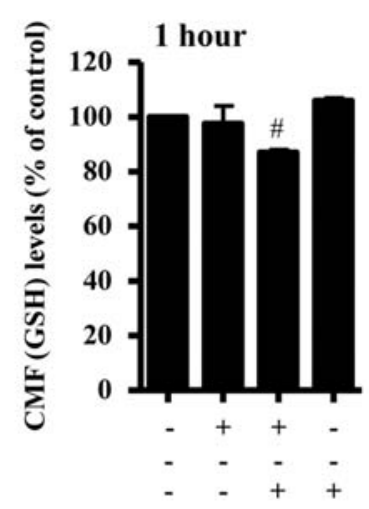

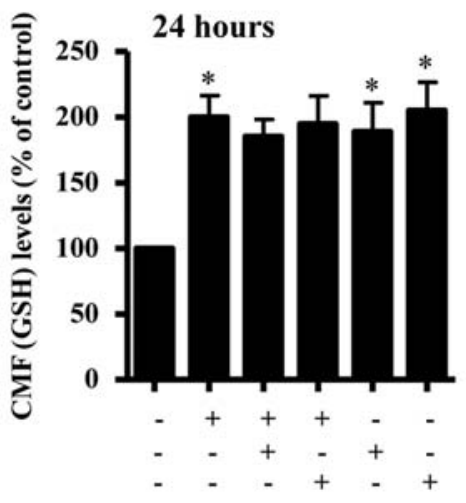

Figure 5. Effects of MG132 on GSH levels in PG-treated HeLa cells. Exponentially growing cells were treated with PG and/or MG132 for 1 or 24 h. GSH levels in HeLa cells were measured using a FACStar flow cytometer. (A) Histograms for CMF intensity in HeLa cells at 24 h. M1 indicates GSH depleted cells. M2 indicates cells excluding GSH depleted cells. (B and C) Graphs show the percent of GSH depleted cells [M1 region in (A)] (B) and mean CMF (GSH) levels [M2 region in (A)] compared with the control group (C). ${ }^{*} \mathrm{P}<0.05$ compared with cells treated with PG only. 
significantly change GSH level at $1 \mathrm{~h}$ but MG132 decreased GSH level in PG-treated cells (Fig. 5C). At 24 h, PG significantly increased GSH levels (excluding GSH depleted cells) and MG132 did not change the GSH levels (Fig. 5A and C). MG132 alone significantly increased GSH levels in HeLa control cells (Fig. 5A and C).

\section{Discussion}

Treatment with MG132 intensified the growth inhibition and apoptosis in PG-treated HeLa cells. MG132 alone significantly induced cell growth inhibition and cell death in HeLa cells. MG132 significantly decreased the number of cells at G1 phase in PG-treated HeLa cells. The proportion of a G1 phase in PG and/or MG132-treated HeLa cells seemed to be affected by the changes of p27 protein levels, which was clearly regulated by these agents. In addition, MG132 increased the level of MMP $\left(\Delta \Psi_{\mathrm{m}}\right)$ loss in PG-treated cells but did not alter $\operatorname{MMP}\left(\Delta \Psi_{\mathrm{m}}\right)$ level in these cells, implying that MG132 affects MMP $\left(\Delta \Psi_{\mathrm{m}}\right)$ loss rather than MMP $\left(\Delta \Psi_{\mathrm{m}}\right)$ level in PG-treated HeLa cells. These data suggest that the inhibition of ubiquitinproteasomal system by MG132 is involved in cell growth inhibition (or via cell cycle distribution changes) and cell death [or via MMP $\left(\Delta \Psi_{\mathrm{m}}\right)$ loss] in PG-treated HeLa cells.

Similar to previous reports $(20,22)$, ROS levels including $\mathrm{O}_{2}{ }^{-}$levels were increased or decreased in PG-treated HeLa cells depending on the incubation times ( 1 or $24 \mathrm{~h}$ ). MG132 also increased the intracellular ROS levels including $\mathrm{O}_{2}{ }^{--}$in HeLa control cells. It is reported that PG or MG132 induced cell death by mediating mitochondrial dysfunction $(18,28)$. Likewise, PG or MG132 induced the loss of MMP $\left(\Delta \Psi_{\mathrm{m}}\right)$ and increased mitochondrial $\mathrm{O}_{2}{ }^{-}$levels in HeLa cells. In relation to the effect of MG132 on ROS levels in PGtreated HeLa cells, MG132 enhanced ROS (DCF) levels in these cells. It is possible that this enhancement resulted from the strong down-regulation of catalase expression in PGtreated HeLa cells by MG132. MG132 also increased $\mathrm{O}_{2}{ }^{-}$ levels including mitochondrial $\mathrm{O}_{2}{ }^{-}$in PG-treated HeLa cells without changing SOD expression level. Therefore, it was plausible that the increased $\mathrm{O}_{2}{ }^{--}$levels by PG and/or MG132 was due to the mitochondrial dysfunction by these agents. Correctively, these results suggest that the inhibition of proteasome by MG132 plays a role as an enhancement factor in PG-induced apoptosis in HeLa cells by increasing ROS levels including mitochondrial $\mathrm{O}_{2}{ }^{\cdot-}$.

Apoptotic effects are inversely comparative to GSH content $(29,30)$. In addition, it is reported that GSH depletion due to proteasome inhibitors may lead to cell death $(18,19)$. Likewise, PG and/or MG132 increased GSH depleted cell numbers in HeLa cells. It is of note that GSH levels (excluding GSH depleted cells) in PG and/or MG132-treated HeLa cells were increased at $24 \mathrm{~h}$. Probably, these happened to reduce the increasing ROS by these agents. Thus, cells beyond their capacity to resist ROS seemed to be immediately dead. However, PG or MG132 alone did not alter GSH content in HeLa cells at $1 \mathrm{~h}$, and co-treatment with PG and MG132 reduced GSH levels in HeLa cells. These results suggest that PG and/or MG132 differently regulate GSH levels in HeLa cells depending on the incubation times.
In conclusion, the inhibition of proteasome by MG132 plays a role as an enhancement factor in PG-induced apoptosis in HeLa cells via increasing ROS levels and GSH depletion.

\section{Acknowledgements}

This study was supported by a grant from the Ministry of Science and Technology (MoST)/Korea Science and Engineering Foundation (KOSEF) through the Diabetes Research Center at Chonbuk National University (2010-0029497) and the National Research Foundation of Korea Grant funded by the Korean Government (MEST) (2010-0021808).

\section{References}

1. Daniel JW: Metabolic aspects of antioxidants and preservatives. Xenobiotica 16: 1073-1078, 1986

2. Rosin MP and Stich HF: Enhancing and inhibiting effects of propyl gallate on carcinogen-induced mutagenesis. J Environ Pathol Toxicol 4: 159-167, 1980.

3. Abdo KM, Huff JE, Haseman JK and Alden CJ: No evidence of carcinogenicity of D-mannitol and propyl gallate in F344 rats or B6C3F1 mice. Food Chem Toxicol 24: 1091-1097, 1986.

4. Reddan JR, Giblin FJ, Sevilla M, Padgaonkar V, Dziedzic DC, Leverenz VR, Misra IC, Chang JS and Pena JT: Propyl gallate is a superoxide dismutase mimic and protects cultured lens epithelial cells from $\mathrm{H}_{2} \mathrm{O}_{2}$ insult. Exp Eye Res 76: 49-59, 2003.

5. Chen $\mathrm{CH}$, Liu TZ, Chen $\mathrm{CH}$, Wong $\mathrm{CH}$, Chen $\mathrm{CH}$, Lu FJ and Chen SC: The efficacy of protective effects of tannic acid, gallic acid, ellagic acid, and propyl gallate against hydrogen peroxideinduced oxidative stress and DNA damages in IMR-90 cells. Mol Nutr Food Res 51: 962-968, 2007.

6. Hirose M, Yada H, Hakoi K, Takahashi S and Ito N: Modification of carcinogenesis by alpha-tocopherol, t-butylhydroquinone, propyl gallate and butylated hydroxytoluene in a rat multi-organ carcinogenesis model. Carcinogenesis 14: 2359-2364, 1993.

7. Kobayashi H, Oikawa S, Hirakawa K and Kawanishi S: Metalmediated oxidative damage to cellular and isolated DNA by gallic acid, a metabolite of antioxidant propyl gallate. Mutat Res 558: 111-120, 2004.

8. Kawanishi S, Oikawa S and Murata M: Evaluation for safety of antioxidant chemopreventive agents. Antioxid Redox Signal 7: 1728-1739, 2005

9. Nakagawa Y, Nakajima K, Tayama S and Moldeus P: Metabolism and cytotoxicity of propyl gallate in isolated rat hepatocytes: effects of a thiol reductant and an esterase inhibitor. Mol Pharmacol 47: 1021-1027, 1995.

10. Han YH, Moon HJ, You BR, Yang YM, Kim SZ, Kim SH and Park WH: Propyl gallate inhibits the growth of endothelial cells, especially calf pulmonary arterial endothelial cells via caspaseindependent apoptosis. Int J Mol Med 25: 937-944, 2010.

11. Han YH, Moon HJ, You BR and Park WH: Propyl gallate inhibits the growth of calf pulmonary arterial endothelial cells via glutathione depletion. Toxicol In Vitro 24: 1183-1189, 2010.

12. Jacobi H, Eicke B and Witte I: DNA strand break induction and enhanced cytotoxicity of propyl gallate in the presence of copper(II). Free Radic Biol Med 24: 972-978, 1998.

13. Orlowski RZ: The role of the ubiquitin-proteasome pathway in apoptosis. Cell Death Differ 6: 303-313, 1999.

14. Voges D, Zwickl P and Baumeister W: The 26S proteasome: a molecular machine designed for controlled proteolysis. Annu Rev Biochem 68: 1015-1068, 1999.

15. Lee DH and Goldberg AL: Proteasome inhibitors: valuable new tools for cell biologists. Trends Cell Biol 8: 397-403, 1998.

16. Wu HM, Chi KH and Lin WW: Proteasome inhibitors stimulate activator protein-1 pathway via reactive oxygen species production. FEBS Lett 526: 101-105, 2002

17. Perez-Galan P, Roue G, Villamor N, Montserrat E, Campo E and Colomer D: The proteasome inhibitor bortezomib induces apoptosis in mantle-cell lymphoma through generation of ROS and Noxa activation independent of p53 status. Blood 107: 257-264, 2006.

18. Ling YH, Liebes L, Zou Y and Perez-Soler R: Reactive oxygen species generation and mitochondrial dysfunction in the apoptotic response to Bortezomib, a novel proteasome inhibitor, in human H460 non-small cell lung cancer cells. J Biol Chem 278: 33714-33723, 2003. 
19. Qiu JH, Asai A, Chi S, Saito N, Hamada H and Kirino T: Proteasome inhibitors induce cytochrome c-caspase-3-like protease-mediated apoptosis in cultured cortical neurons. J Neurosci 20: 259-265, 2000.

20. Han YH and Park WH: Propyl gallate inhibits the growth of HeLa cells via regulating intracellular GSH level. Food Chem Toxicol 47: 2531-2538, 2009

21. Han YH, Moon HJ, You BR and Park WH: The anti-apoptotic effects of caspase inhibitors on propyl gallate-treated HeLa cells in relation to reactive oxygen species and glutathione levels. Arch Toxicol 83: 825-833, 2009.

22. Han YH, Moon HJ, You BR and Park WH: The effect of MG132, a proteasome inhibitor on HeLa cells in relation to cell growth, reactive oxygen species and GSH. Oncol Rep 22: 215-221, 2009 .

23. Han YH, Kim SZ, Kim SH and Park WH: Arsenic trioxide inhibits growth of As4.1 juxtaglomerular cells via cell cycle arrest and caspase-independent apoptosis. Am J Physiol Renal Physiol 293: F511-F520, 2007

24. Han YH, Kim SZ, Kim SH and Park WH: Pyrogallol inhibits the growth of human lung cancer Calu-6 cells via arresting the cell cycle arrest. Toxicol In Vitro 22: 1605-1609, 2008.
25. Park WH, Park MN, Han YH and Kim SW: Pyrogallol inhibits the growth of gastric cancer SNU-484 cells via induction of apoptosis. Int J Mol Med 22: 263-268, 2008.

26. Han YH, Kim SZ, Kim SH and Park WH: Pyrogallol as a glutathione depletor induces apoptosis in HeLa cells. Int J Mol Med 21: 721-730, 2008.

27. Lazebnik YA, Kaufmann SH, Desnoyers S, Poirier GG and Earnshaw WC: Cleavage of poly(ADP-ribose) polymerase by a proteinase with properties like ICE. Nature 371: 346-347, 1994.

28. Nakagawa Y and Tayama S: Cytotoxicity of propyl gallate and related compounds in rat hepatocytes. Arch Toxicol 69: 204-208, 1995.

29. Estrela JM, Ortega A and Obrador E: Glutathione in cancer biology and therapy. Crit Rev Clin Lab Sci 43: 143-181, 2006.

30. Park WH, Han YW, Kim SH and Kim SZ: A superoxide anion generator, pyrogallol induces apoptosis in As4.1 cells through the depletion of intracellular GSH content. Mutat Res 619: 81-92, 2007. 